\title{
III. Description of the equus hemionus or dfhiggetai of the Eastern deserts of Middle Asia
}

\section{Professor Pallas}

To cite this article: Professor Pallas (1798) III. Description of the equus hemionus or dfhiggetai of the Eastern deserts of Middle Asia, Philosophical Magazine Series 1, 2:7, 234-240, DOI: $10.1080 / 14786449808676913$

To link to this article: http://dx.doi.org/10.1080/14786449808676913

$$
\text { 曲 Published online: } 18 \text { May } 2009 .
$$

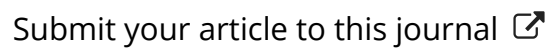

Џ Article views: 3 
of the day; but the fmall pennons at the maft-heads of the filhing-boats in the harbour were in the morning at all points of the compafs.

I was a few days afterwards at Winchelfea, and at feveral places along the coaft; where I was informed the above phenomenon had been equally vifible.

III. Defcription of the Equus Hemionus or Dhiggetai of the Eaftern Dejerts of Middle Afia. By Profefor Pallas. From Neue Nordifche Beytrage, Vol. II.

[Concluded from page 121.]

$\mathrm{T}$ $\mathrm{HE}$ covering feafon of the dhiggetai falls towards the middle or end of Auguft ; and about this period Mefferfchmidt obferved in a female, which he diffected, a fotus not larger than a moufe. They caft their young in the fpring, and generally have one foal at a time. When the young attain to the age of three, they are equal in fize to the old ones, and are fit for procreation, as I was affured by the inhabitants of thofe countries, who often had an opportunity of killing and examining thefe animals.

The males when they fight bite each other, like the common wild horfes. The dihiggetai fights alfo with its heels, as was obferved in a foal which had been caught, and which, a few years before my arrival in Dauuria, was kept there by one of the Coffacks; but it continued alive only a fhort time. The hair of the dhiggetai in winter is almoft of a pale ifabeila yellow colour, about an inch and a half Jong; a little rough on the back, as was the cafe in the foal of a wild horfe, which I have already defcribed *, and equally foft and tender. Skins covered with winter bair of this kind I have found among the Tungufians. The female, however, which I procured in Dauuria, at the end of the month

* See Pallas Revise, rul. iii. f. 509, Plate VIII. 
of May, had at that period loft almoft all its winter hair, though the Tungufian horfes ftill retained theirs. The fummer bair of this female was uncommonly fmooth and pretty; and I never found it much longer on the Rins of animals thot far later in the feafon. The colour eafily becomes paler; and on the ftuffed hide of the female, which I have defcribed, and which is preferved in the cabinet of natural hiftory at Peterfburgh, the fummer hair, partly by the preparation the hide has gone through, and partly by the effects of the fun, has been totally bleached to a dull ifabella colour, which appears lighter than the common winter hair.

The above female was about three years old, and was fhot on the 26th of May O. S. 1772, in the neighbourhood of Tareinoor, in the country of the Tungufians. As the fpring heats had then commenced with great violence in thofe diftricts, the animal, at Kuluffutai, where it was kept for me, had already begun to putrefy on the $28 \mathrm{th}$, and expofed me to a very difagreeable piece of labour, efpecially in a barren region, where $I$ was obliged to diffect it without any affitance. The figure (Plate V.) done from a drawing made before the diffection, is fo accurate, that I was never better fatisfied with any reprefentation of an animal. The diniggetai cannot, therefore, be any longer confidered among the doubtful animals, and its defcription is as follows :

In fize and figure it has a great refemblance to a middlefized mule; but it excels the mule in the beauty and delicacy of its make. The head is larger than that of the horfe, and more compreffed at the fides; the forehead is perfectly flat, and runs downwards with a fmall angle towards the muzzle. The fides of the head are allo flat, efpecially where the broad part of the jaw-bones lie, and where the head has the greateft thicknefs. On the other hand, the throat, between the broad parts of the jaw-bones, is hollow.

The lips, particularly the upper one, are thick and fabby; thinly covered with bair, and black an the edges, which are 
Philosophical Mag.PL.V.Vol.II. Chich WolfOrog.

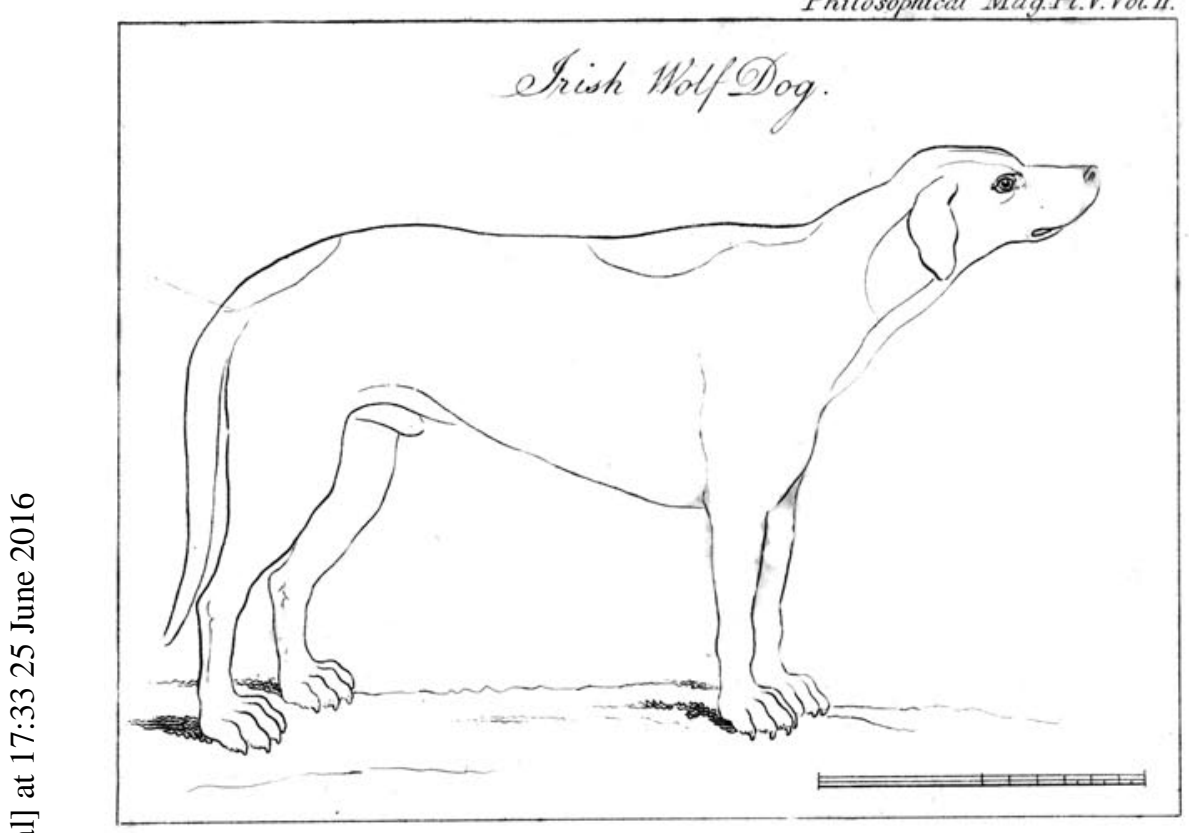

Mild Ifs of Niddle tria.

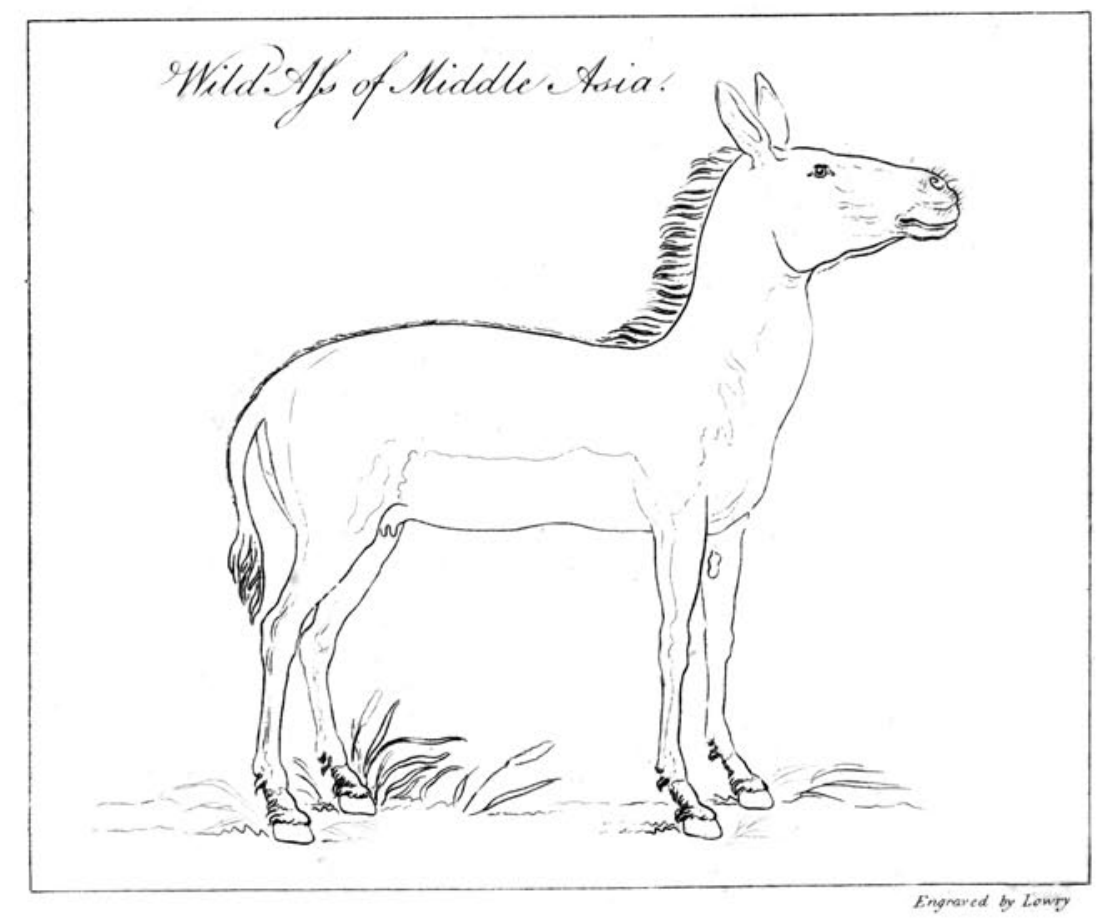


befet with ftiff gray briftes, crooked and bent downwards. The corners of the mouth are covered with foft hair on the infide; and the inner fide of the cheeks is covered with fine blackin glands. The number of the teeth amounts to thirty-four; fo that this animal has two lefs than the horfe. The fore-teeth are fix ; the four middlemoft of which, in the above-mentioned female, had not yet been changed; they were of a conical form marked with a fmall furrow; and the fide ones were obliquely blunted, and preffed towards thofe in the middle. The fituation of the fore-teeth is the fame as thofe of the horfe, ftanding perpendicular in the upper, and obliquely in the under jaw. I found the eyeteeth neither in this female, nor in the kull of a ftallion, which had been not a little before, and brought to me by the Tungufians; but $I$ obferved in the upper jaw of the former, at a mean difance between the fore and jaw teeth, a trace as of a focket for a tooth. The jaw-teeth were like thofe of the horle; but on each fide above, as well as below, there were only three fully grown, beyond which the fourth was juft beginning to appear. I found a fifth in the beforementioned ikull concealed within the focket. Of the latter, Mefferfchmidt, fpeaking of the fkull of a ftallion, makes no mention. In the palate I counted feventeen broad wrinkles, of which, thofe before were flatter, and thofe behind higher and broader.

The noftrils, as in the horfe, are wide, blackifh on the infide and edges; but under the noftril, on each fide of the cartilage, there is an excrefcence like a large round wart, which is to be found neither in the horfe nor the afs. The muzzle is interfperfed with long blackifh briftes, the longeft of which, about two incbes in length, are found on the underlip, and on the outfide of the noftrils.

The eyes are of a muderate fize, and, with their longe? diameter, ftand in the hcad obliquely. The edges of the eyelids and a triangular fot at the corner of the eye are bald and blacking; and the upper eyelid only is furnithed 
with a row of black eyelafhes, feven lines in length, which are at a little diftance from the edge of the cyelid, and do not reach entirely to the corners. Below the foremoft corner, however, of the eye, in the neighbourhood of the os jugalis, there are feveral fcattered black hairs, two of which, more than two inches in length, lie entirely flat. In the corner of the eye lies a thick white fold of $\mathrm{kin}$, which is capable of being extended, feven lines in breath, as far as the iris, and in the middle of its edge has a blackith moonformed fpot. The white of the eye, next to the tranfparent cornea, is brownilh; the iris is darkifh gray, and, as it were, radiated with folds; the pupil is elongated, fo that its longeft diameter runs through the corner of the eye, and, like the eye itfelf, fands obliquely.

The ears are much larger than thofe of the horfe, though much more in proportion to the fize than thofe of the afs; tharp-pointed, erect, internally of the colour of the body; but the infide, at the top, and a ftripe on the edges downwards, are brownifh black. On the infide they are covered with curled whitih hair, which rifes up from the circumference. Three raifed ftripes run along the infide of the ear lengthwife, which are thinly covered with hair of the like kind projecting from each other.

The neck is fmaller and rounder than that of the horfe, and even than that of thofe called ftag-necked. The mane proceeds from the back part of the fkull to the Moulders, of an equal height, and is as foft and as upright as in young foals. It is of a blackin colour with yellowith gray points, and about three quarters of an inch in length. Inftead of the tuft before, the whole fpace between the ears and the orbits of the eyes is thick fet with foft hair of the fame colour as the mane, and at moft one inch three lines in length.

The body is pretty long, more compreffed on the fides than in the horfe, contracted towards the lower part of the brealt, particularly before, into a conical form, and ftrongly 
buitt. The rump is pretty traight and fomewhat harp, as in the afs. As the body was fwelled up, the fine was become bent into the form of a bow.

The animal ftands high on its limbs, which are delicate, though its mufcles are ftrong; but the Moulders, thighs and legs are fomewhat meagre, like thofe of flight-formed mules. The fore legs, on the infide, have a longih, round, bald, blackifh fcar, covered with a tender, fomewhat hard and brittle $\mathrm{fkin}$, which, at fome times of the year, may perhaps be covered hy a corneous fubfance. In the common afs this fcar is more of a round form. It was in length two inches feven lines, and in breadth orfe inch fix lines. On the hind legs no traces of fuch a far were to be feen. The lower part of the leg is perfectly finoath, ornamented behind with a confiderable tuft of thort hair : on the fore-fide inwards there is a black fpot, and outwards a faint mark near the before-mentioned tuft.- On the hind feet there are two fmall faint fpots above it. The hoofs are very hard, dry, of a black colour, fmall, and almoft like a half cone; roundilh-above, and very hollow on the fole. The edges of all the hoofs exhibited traces of cracks which had grown up again.

The tail was almoft like that of a cow; the trunk is thin, moderately long, perfectly round, quite bald from the rump to the middle; but the other part is covered with fhort briftles of the fame culour as the fides of the body. It is buhy at the end, where it forms a black tuft, about nine inches in length.

I found the winter hair on the fkin already mentioned to be two inches long, tolerably thick, as foft as camel hair, and of an ifabella gray colour outwardly, but of a pale irongray towards the roots. The fummer hair on the female, which I have defcribed, was farcely three quarters of a line in length, here and there difpofed into circular arrangements (rortices) and thadings, and on the back never turned forwards as in the zebra. A thading of the hair runs length- 


$$
\text { or Djbiggetai of Middle Afa. }
$$

thife along the face, and two others above the eyes. The vortices I obferved firft on each fide of the mane immediately bebind the ears. There were two alfo: above each other under the neck; I wo on the fides of the neck oppofite the Moulders; a larger one on each joint of the fhonlder; another large one on each fide of the breaft behind the fhoul ders, and alfo a cruciform thading of the hair. Several more of thefe hair vortices could be obferved on different parts of the body.

The colour of the muzzle is whitith; the reft of the body inclines a little more to yellow; the neck is of a fallow colour; the rump from the back to the fides of an ochre yellow; the fides fallow, and the limbs paler. The hind part of the fore legs, and the inner part of the hind legs, together with the lower part of the rump and the hinder edge of the thigh, are whitifh. Where the mane ceafes, there begines a blackif brown fripe, which runs along the ridge of the back to the buthy part of the tail. The udder is blackifh and perfectly bald, with two ftrong thort teats. The meafurement of the principal parts of this animal is as follows: The length from the firul between the ears to the root of the tail 5 feet $I$ inch 3 lines; length of the head $x$ fout 8 inches 6 lines; height of the animal at the fhoulders before 3 feet 9 inches 9 lines; height behind 4 feet 3 inches 6 lines; length of the ears 7 inches 2 lines; length of the tail without the brum at the end I foot 4 inches $I$ line: length of the brufh 8-inches 2 lines. The weight of the whole animal amounted to 560 pounds apothecary's weight.

Every think confidered, the dhiggetai is diftinguifhed particularly by the head, which has a mean proportion botween that of the horfe and the afs; and, in that refpect, as well as by the ears and the tail, it approaches very near to the zebra. In the reft of the body and the thighs it is more like the afs; and in the limbs it has a greater fmilarity to the mule and the horfe. The tail is more naked than that of the afs, and nearly like that of the cow. Its 
colour and hair yortices are peculiar to itfelf. The ftripe on the back, however, is like that of the female onager, and of many horfes, without any crofs ftripes. The tail excepted, it has, in general, the greateft likenefs to the mule. But, from the above circumftances, it clearly appears that the dihiggetai is an animal of a diftinct genus, and as much peculiar to Afia as the zebra and quagga are to Africa; whereas the afs, and perhaps the horfe, in a wild ftate, belong to both thefe quarters of the world in common.

IV. Experiments on, and the Manner of diftinguifbing; /everal Dijeafes by the Urine. By $M r$. CRUickshank. Front Cafes of the Diabetes, \&c. Second Edition.

THE wrine is a fluid feparated from the blood by the kidneys, containing feveral neutral falts, with more or lcfs animal extractive matter. The relative proportions of thefe fubftances are found to vary fo much in the fame perfon, both in health and difeafe, that it is extremely difficult to fix on what may be confidered as a ftandard for healthy urine. The fpecific gravity of this fluid reaches from 1005 to 1033 , that of diftilled water being 1000 : by expofure to the air it foon runs into the putrefactive ftate, accompanied with the production of much ammonia, although when firt voided it always contains an excefs of phofphoric acid, and reddens litmus : in confequence of this excefs, it holds in folution more or lefs phofphat of lime, which may be readily thrown down by a fixed alkali, or even pure ammonia. By evaporation, $3^{6} \mathrm{oz}$. yield a refiduum varying from $I$ oz. to $I \frac{1}{2}$ : this confifts of the muriats of potafh and foda, the phofphats of foda, lime, and ammonia, the phof phoric and lithic acids, with animal extractive, matter. Their relative proportions in a healthy fate may be nearly as follow's : 